\title{
Phenolic Profile, Nutritional Composition, Functional Properties, and Antioxidant Activity of Newly Grown Parthenocarpic and Normal Seeded Tomato
}

\author{
Sajid Dominic, ${ }^{1}$ Abdullah Ijaz Hussain ${ }^{D},{ }^{2}$ Shahzad Ali Shahid Chatha, ${ }^{2}$ Qasim Ali, ${ }^{3}$ \\ Nosheen Aslam, ${ }^{4}$ Satyajit Dey Sarker, ${ }^{5}$ Saeed Ahmad Shah Chishti, ${ }^{6}$ Shafaqat Ali $\mathbb{D},{ }^{7,8}$ \\ Saliha Maqbool, ${ }^{9}$ Mohamed A. El-Sheikh, ${ }^{10}$ and Mohammed Nasser Alyemeni ${ }^{10}$ \\ ${ }^{1}$ Department of Applied Chemistry, Government College University, Faisalabad, Pakistan \\ ${ }^{2}$ Natural Product and Synthetic Chemistry Lab, Department of Chemistry, Government College University, Faisalabad, Pakistan \\ ${ }^{3}$ Department of Botany, Government College University, Faisalabad, Pakistan \\ ${ }^{4}$ Department of Biochemistry, Government College University, Faisalabad, Pakistan \\ ${ }^{5}$ Centre for Natural Products Discovery, School of Pharmacy and Biomolecular Sciences, Liverpool John Moores University, \\ James Parsons Building, Byrom Street, Liverpool L3 3AF, UK \\ ${ }^{6}$ Hybrid Seed Production (HSP), Ayub Agricultural Research Institute, Faisalabad, Pakistan \\ ${ }^{7}$ Department of Environmental Sciences and Engineering, Government College University, Faisalabad 38000, Pakistan \\ ${ }^{8}$ Department of Biological Sciences and Technology, China Medical University, Taichung 40402, Taiwan \\ ${ }^{9}$ Department of Soil, Water, and Climate, University of Minnesota, Minneapolis, USA \\ ${ }^{10}$ Department of Botany and Microbiology, College of Science, King Saud University, Riyadh 11451, Saudi Arabia
}

Correspondence should be addressed to Abdullah Ijaz Hussain; abdullahijaz@gcuf.edu.pk and Shafaqat Ali; shafaqataligill@gcuf.edu.pk

Received 13 September 2020; Revised 22 August 2021; Accepted 22 September 2021; Published 3 November 2021

Academic Editor: Manuela Curcio

Copyright (C) 2021 Sajid Dominic et al. This is an open access article distributed under the Creative Commons Attribution License, which permits unrestricted use, distribution, and reproduction in any medium, provided the original work is properly cited.

The aim of the study was to compare the physicochemical parameters, sugar, vitamin C, and phenolic profiles in five genotypes of local indeterminate tunnel tomato hybrid (LITTH) (LITTH-778, LITTH-784, LITTH-786, LITTH-788, and LITTH-790) of natural parthenocarpic tomato (NPT) and normal seeded tomato (NST). Samples were collected from the experimental fields of Ayub Agricultural Research Institute, Faisalabad, Pakistan. Physical parameters (fruit shape, fruit weight, fruit length, fruit width, number of seeds per fruit, and shelf-life) and chemical composition (moisture, ash, crude fat, crude fiber, total carbohydrate, crude protein, and vitamin C) of NPT and NST were analyzed by reported methods. The methanolic extracts of tomato pulp were prepared by shaking and extracts were assayed for antioxidant activity. Sugar contents and phenolic profile of NPT and NST were estimated using HPLC method. Weight and size of NPT were less and smaller than the NST. Moreover, NPT were seedless with longer shelf-life and had more phenolic and flavonoid contents than the NST. HPLC analysis revealed that chlorogenic acid, gallic acid, and $p$-coumaric acid were major phenolics in methanol (polar solvent) extracts of NST, and caffeic acid, gallic acid, and $p$ coumaric acid in NPT extract. NPT contained higher concentration of sugar contents, but lower concentration of vitamin C than NST. In 2,2-diphenyl-1-picrylhydrazyl (DPPH) free radical scavenging assay, NPT fruit extracts showed high scavenging activity with the $50 \%$ inhibitory concentration (IC50) value of $22.56 \mu \mathrm{g} / \mathrm{mL}$ compared to NST fruit extracts having $\mathrm{IC}_{50} 29.49 \mu \mathrm{g} / \mathrm{mL}$. This study provided useful information for farmers and nutritionists. 


\section{Introduction}

Tomato (Lycopersicon esculentum) fruits are an essential part of human diet and have extensive health benefits [1]. Tomato fruits are an excellent natural supplement of minerals, essential nutrients, and many other secondary metabolites such as lycopene, carotene, vitamin C, and polyphenols $[2,3]$. Due to these valuable nutrients, utilization of tomatoes can decrease the risk of various fatal diseases such as cancer and coronary artery diseases $[4,5]$.

Parthenocarpy means "virgin fruit" in biological term can be introduced naturally or artificially for the development of fruits without the process of fertilization, which results in seedless fruits $[6,7]$. Trend for the development of seedless fruits is increasing because seeds are bitter in taste, leathery, or hard textured and may accumulate harmful compounds in many instances [8,9]. According to the consumers demand and better nutritional quality, absence of seeds and seed cavities from many fruits is required $[8,10]$. Moreover, presence of seeds accelerates the deterioration process of the fruits due to various chemicals present in them $[10,11]$. Thus, seedlessness may also increase the shelf-life of the fruits $[12,13]$.

Various parthenocarpy approaches are effective, which involve the specific mutations such as introduction of specific genes and the use of different chemicals [12]. In Italy, parthenocarpic tomatoes were developed in the Italian variety "Sha-pat" using the temperature effect and pollination method [14]. Utilization of phytohormones such as auxin and gibberellin, especially the auxins, is a chemical approach to induce parthenocarpy in fruits $[15,16]$. Some adverse environmental factors were also found effective and are in use to introduce parthenocarpy in fruits including low and high temperatures, intensity of light, humidity, and rainfall etc. [17]; among these, temperature is the most effective one to introduce parthenocarpy.

Reported data also explained the development of parthenocarpic fruit, in tomato line, "Oregon T5-4" below $18^{\circ} \mathrm{C}$ [18]. However, not a single report is available on the effect of parthenocarpy on the physiochemical properties, nutritional quality, phenolic profile, vitamin content, and antioxidant potential of selected genotype in comparison with normal seeded fruits. Thus, in this study we planned to explore the variation in the physical parameters (fruit shape, fruit weight, fruit length, fruit width, number of seeds per fruit, and shelf-life of fruit), proximate composition, antioxidant activity total phenolic contents (TPC), total flavonoid contents (TFC), 2,2-diphenyl-1-picrylhydrazyl (DPPH) free radical scavenging activity, reducing power, and nutritional quality parameters (sugars, vitamin $\mathrm{C}$, phenolic, and flavonoids) of natural parthenocarpic tomato (NPT) and normal seeded tomato (NST).

\section{Materials and Methods}

2.1. Sample Collection. Mature tomato fruits of five selected genotypes, namely, local indeterminate tunnel tomato hybrid (LITTH-778, LITTH-784, LITTH-786, LITTH-788, and LITTH-790), of NST and NPT were harvested at fully ripen stage from the experimental fields of Vegetable Research Department, Ayub Agricultural Research Institute (AARI), Faisalabad, Pakistan. Polythene bags were used to pack fruits and then stored in a refrigerator at $4^{\circ} \mathrm{C}$ for the preservation of essential nutrients.

2.2. Physical Parameters of Tomato Fruits. For the measurement of different physical parameters of the fruits, twelve fully ripened fruits of each tomato genotype were selected randomly. Each fruit was weighed by using electronic balance, reading with the accuracy of $0.001 \mathrm{~g}$ to measure the fresh masses. Length and width of the fruits were measured by using the vernier caliper having $0.01 \mathrm{~mm}$ accuracy. Fruits seeds were counted by dissecting them diagonally. Shelf-lives of collected tomatoes were measured as reported [19].

2.3. Proximate Analysis. The moisture contents of tomato fruits were determined as reported by Osbome and Voogt [20]. Preweighed crucible with $2 \mathrm{~g}$ grounded sample was taken and placed in oven for 24 hours at $102^{\circ} \mathrm{C}$, till last fixed weight was obtained. Estimation of ash contents was performed according to method of AOAC [21]. Preweighed empty crucible with $2 \mathrm{~g}$ of dry sample was taken and then placed in Muffle Furnace along with sample at $600^{\circ} \mathrm{C}$ till obtaining the white ash. For the estimation of crude fiber, AOAC method was used [21]. Briefly, for half an hour, $2 \mathrm{~g}$ of each tomato sample was boiled with $0.12 \mathrm{~N}$ in $250 \mathrm{ml}$ of $\mathrm{H}_{2} \mathrm{SO}_{4}$. The obtained residue after filtration was washed with distilled water. After it, for half an hour the residue was boiled with $0.313 \mathrm{~N}$ in $250 \mathrm{~mL}$ of $\mathrm{NaOH}$ followed by the filtration and washing. The residue was weighed after drying completely and then heated in furnace until ash was formed by the residue and then the ash was weighed. Crude fiber content was determined according to the method reported [21]. $2 \mathrm{~g}$ weighed sample was put into thimble and dried in hot circulating air oven at $98^{\circ} \mathrm{C}$ for overnight. Take sample from the oven and cool it and then prepare extract of it with $100 \mathrm{~mL}$ of diethyl ether in a Soxhlet extractor attached with preweighed round bottom flask for 8 to 12 hours. Total carbohydrate content was measured as reported [22]. Total carbohydrate of tomato sample was measured by subtracting the sum of the $\%$ ash, $\%$ moisture, crude fiber, and crude protein from $100 \%$. Crude protein was estimated by using AOAC method [21]. Briefly, $6.25 \mathrm{~g}$ of each tomato sample was put on nitrogen-free filter paper. This $\mathrm{N}_{2}$-free filter was folded properly and then transferred to Kjeldahl digestion tubes. Digest catalyst $\left(\mathrm{CuSO}_{4}+\mathrm{Na}_{2} \mathrm{SO}_{4}\right)$ of $3 \mathrm{~g}$ and $25 \mathrm{~mL}$ of concentrated sulphuric acid were poured to each digestion tube. This digested tube was transferred to Kjeldahl digestion apparatus and then heated at below the boiling point of acid. Resulting mixture after the digestion was poured in separate $100 \mathrm{~mL}$ flasks (volumetric) and diluted with distilled $\mathrm{H}_{2} \mathrm{O}$ to make the volume up to $100 \mathrm{~mL}$. Each digested sample was transferred into distillation jacket of microsteam distillation apparatus. About $200 \mathrm{~mL}$ of $\mathrm{NaOH}(40 \%$ w/v) solution was poured to each digest of distillation jacket; then $50 \mathrm{~mL}$ of boric acid $(40 \% \mathrm{w} / \mathrm{v})$ solution was poured into another 
conical flask by the addition of four drops of methyl red indicator. Ammonia was collected through the condenser. The process of distillation was proceeding smoothly unless about $25 \mathrm{~mL}$ of distilled water was trapped in boric acid by changing the color from red to yellow. The resulting mixture was titrated against $0.02 \mathrm{M} \mathrm{HCl}$ and mean reading was recorded. \% Nitrogen was first calculated and crude protein was determined by multiplying the $\mathrm{N}$ with a factor of 5.3 .

\subsection{Preparation of Methanol Extract. Methanol (MeOH)} extract of NPT and NST fruits was prepared using orbital shaker due to its high polarity [23]. Tomato fruits were dried at room temperature for about two weeks till a constant weight was achieved. After grinding, 80 mesh $50 \mathrm{~g}$ material was soaked in $500 \mathrm{~mL}$ absolute $\mathrm{MeOH}$ for $24 \mathrm{~h}$ using orbital shaker (Gallen Kamp, England) at $140 \mathrm{rpm}$. All the extracts were filtered using Whatman No. 1 filter paper and resolute using rotary vacuum evaporator (BRE-225 Robus Technologies) and then weighed for yield estimation. The extracts were stored at $4 \mathrm{C}$ until used for analysis.

2.5. Evaluation of the Antioxidant Activity of the Extracts. Amount of total phenolic content (TPC) from tomato extracts was calculated using Folin Ciocalteu phenol reagent as reported [24]. The method reported by Hussain et al. [24] was followed for the measurement of total flavonoid content (TFC) of the tomato extracts. To measure the free radical scavenging activity of tomato extracts, the DPPH assay was followed as reported [24].

2.6. Qualitative and Quantitative Analysis of Phenolic Acids and Flavonoids Using HPLC. The hydrolysis of tomato fruit extracts was achieved as reported previously [24]. Briefly, dissolve $1 \mathrm{~g}$ of crude tomato extract in $10 \mathrm{~mL}$ of methanol $(50 \% \mathrm{v} / \mathrm{v})$ solution containing ascorbic acid $(0.04 \% \mathrm{w} / \mathrm{v})$ which acts as antioxidant. Three drops of $1.2 \mathrm{M}$ of $\mathrm{HCl}$ were added to the solution and the resulting mixture was refluxed for $2 \mathrm{~h}$ at $80^{\circ} \mathrm{C}$. After the completion of hydrolysis, the resulting mixture was allowed to cool and then volume was made up to $10 \mathrm{~mL}$ with $\mathrm{MeOH}$. The resulting hydrolyzed extract was then filtered, using $0.45 \mu \mathrm{m}$ nonpyrogenic filters before being subjected to injection. Fresh stock solutions of standards were obtained by dissolving pure standard in analytical grade $\mathrm{MeOH}(1000 \mu \mathrm{g} / \mathrm{mL})$. For the preparation of working standard solutions gradual dilution was required with $\mathrm{MeOH}$ having concentration of $0.4-400 \mu \mathrm{g} / \mathrm{mL}$. Calibration curve for each standard was obtained by plotting the concentration against the obtained peak area. Identification and quantification of phenolic acids and flavonoids were performed on an HPLC system (PerkinElmer, USA), facilitated with Flexer Binary LC pump, UV/VIS LC detector (Shelton CT, 06484 USA), oven assisted column at $30^{\circ} \mathrm{C}$, and degasser (DG-20A5), equipped with $\mathrm{C}_{18}$ column (with the specification of $5 \mu \mathrm{m}, \times 250 \mathrm{~mm} \times 4.6 \mathrm{~mm}$ ), working with gradient elution with two solvents [(glacial $\mathrm{CH}_{3} \mathrm{COOH}$ : $\left.\mathrm{H}_{2} \mathrm{O} 0.5 \%\right)$ and $(\mathrm{MeOH}$ : acetonitrile $\left.35: 65)\right]$ using software, version 4.2.6410 for data analysis. Gradient elution was employed for the better separation of phenolic acids and flavonoids. Identification and estimation of phenolics and flavonoids were achieved by measuring the retention time of peaks developed from sample in comparing with external standards.

2.7. Estimation of Ascorbic Acid (Vitamin C). Ascorbic acid contents in tomato fruits were determined using the method reported by Barros et al. [25]. Absorbance of the sample was recorded at $515 \mathrm{~nm}$, using double beam spectrophotometer (Spectrophotometer Analytik Jena, Germany). For the qualitative and quantitative analysis the sample absorbance was compared by the calibration curve of vitamin $\mathrm{C}$ $(5-200 \mu \mathrm{g} / \mathrm{mL})$.

2.8. HPLC Analysis of Sugars in Tomatoes. Solutions of extract $(4 \mathrm{mg} / \mathrm{mL})$ were prepared using $\mathrm{MeOH}$ and demineralized by using cation and anion resins as reported by Alasalvar et al. [26]. Estimation of sugars was done on a Shimadzu HPLC LC-20A framework (Singapore). The HPLC framework comprised a siphon (demonstrating LC20AT Prominence), a dissolvable degasser (display G1322A), and a segment broiler (showing CT 020A/20AC), equipped with a refractive record locator (display RID10A), and was constrained by Shimadzu LC Solution programming. The framework was likewise helped by CBM $20 \mathrm{~A} /$ $20 \mathrm{~A}$ light framework controller. Starch partition was completed on a Bio-Rad Aminex HPX-87K $300 \times 7.8 \mathrm{~mm}$ segment (Cat \# 1250142) with Bio-Rad protect section with ultra-unadulterated $\mathrm{H}_{2} \mathrm{O}$ as versatile stage at a stream rate of $0.50 \mathrm{~mL} / \mathrm{min}$ and $20 \mu \mathrm{L}$ test was infused. Refractive file identifier kept up at $40^{\circ} \mathrm{C}$ was utilized for recognition purposes. External standard was employed for the estimation of sugars by comparing the retention time with standards.

2.9. Statistical Analysis. Three samples of each tomato genotype were collected and analyzed in triplicate and the values were expressed as mean $\pm S D$. The significance differences among the numerical values of NPT and NST were analyzed using one-way analysis of variance (ANOVA) followed by Tukey's test, using Minitab version 18. The level of significance was set at $p \leq 0.05$.

\section{Results and Discussion}

3.1. Physical Parameters. Results for physical parameters of different genotype of NPT and NST are given in Table 1. It was observed that the NPT fruits were of round shapes, while NST fruits were of elongated shapes (Figure 1). Furthermore, NPT fruits were of less weights (18.5-26.2 g) and smaller in length $(27.85-34.11 \mathrm{~mm})$ and width $(29.17-33.65 \mathrm{~mm})$ than those of the NST fruits, respectively, $109.6-127.8 \mathrm{~g}, 71.85-75.95 \mathrm{~mm}$, and $51.85-64.74 \mathrm{~mm}$ (Table 1). Variation was not significant $(p>0.05)$ regarding fruit size among the NST genotypes, but the significant $(p \leq 0.05)$ reduction in fruit size was observed for NPT as 


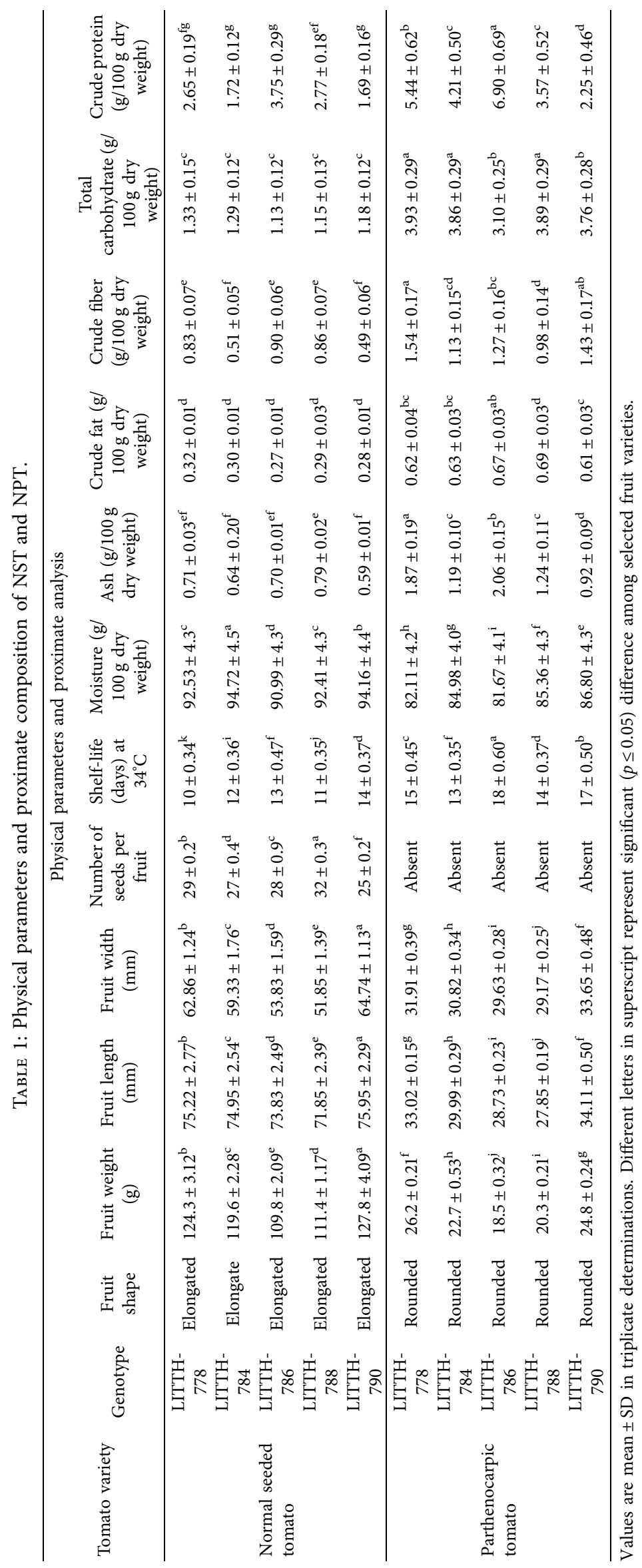




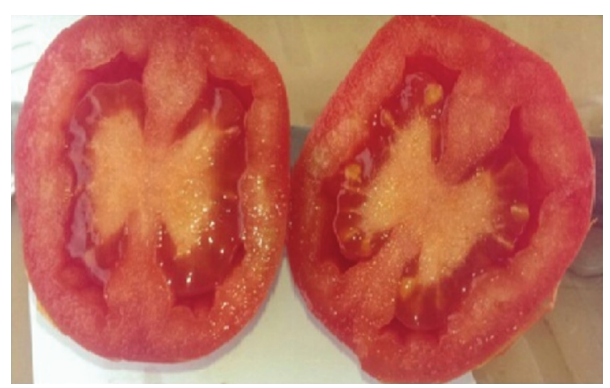

(a)

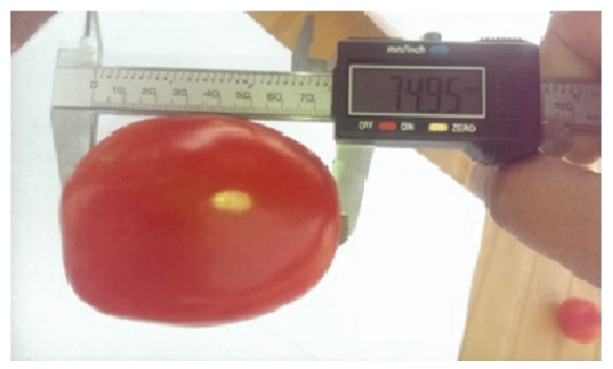

(c)

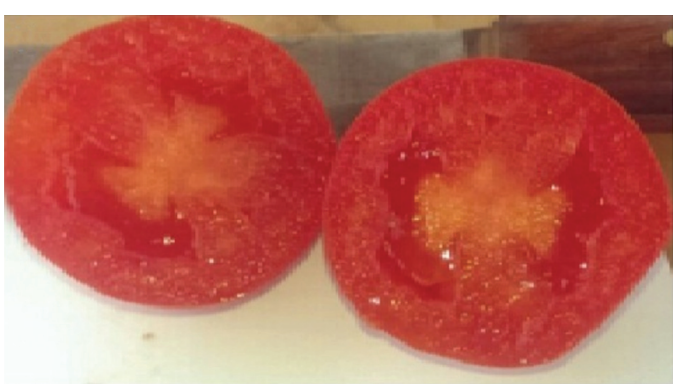

(b)

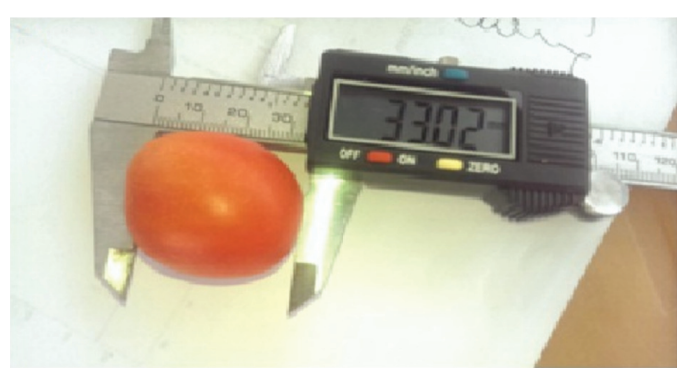

(d)

Figure 1: Normal seeded and parthenocarpic tomatoes. (a) Cross section of normal seeded tomato. (b) Cross section of parthenocarpic tomato. (c) Length of normal seeded tomato. (d) Length of parthenocarpic tomato.

compared with NST. Fruit weight, length, and width of NPT fruits were reduced to the $1 / 3$ of the NST as given in Table 1. Similar results about the fruit shape deformation were observed by the introduction of parthenocarpy [12]. Parthenocarpy effect can reduce the weight and diameter of tomato fruits significantly [27]. The decrease in fruit size in NPT can be compared with the previous literature about parthenocarpic cucumber in which decrease in fruit size was significant due to the introduction of parthenocarpy [28]. Our results were in line with the previously described data about $28-30 \%$ reduction in fruit size due to parthenocarpic effect [27].

NPT fruits had no seeds in all studied genotypes, but the NST fruits of all the genotypes possessed many seeds, 25-32 seeds per fruit (Table 1 and Figure 1). Due to the introduction of parthenocarpic character, the shelf-lives of the NPT increased from 10-12 to 13-22 days compared with NST. Increased shelf-life of the NPT fruits might be due to reduced production of ethylene by seeds [7]. Variations of number of seeds per plant and shelf-life among the genotypes of NPT and NST were significantly $(p \leq 0.05)$ different. Experimental results regarding seeds in NPT fruits were comparable with the studies of [10], where about 10-fold less seeds in parthenocarpic tomato were observed as compared with the control. Reported data described that vitamin $\mathrm{C}$ could reduce the shelf-life of the fruits by thinning the pericarp [19].

3.2. Proximate Composition. The results of proximate analysis for NPT and NST fruits are presented in Table 1. Moisture and ash contents ranged in 92.41-94.72 g/100 g and $0.59-0.79 \mathrm{~g} / 100 \mathrm{~g}$, respectively, in NST and $81.67-86.80 \mathrm{~g} / 100 \mathrm{~g}$ and $0.92-2.06 \mathrm{~g} / 100 \mathrm{~g}$, respectively, in
NPT fruits. NST fruits showed significantly $(p \leq 0.05)$ higher moisture and lower ash contents than the NPT fruits. The results regarding the crude fat and fiber contents are also recorded and given in Table 1. Highest moisture and ash contents were found for LITTH-784 and LITTH-788, respectively, from NST, and LITTH-790 and LITTH-786, from NPT. Moisture and ash contents with minimum concentrations were found in LITTH-786 and LITTH- 790 from NST and LITTH-778 and LITTH-790, respectively, from NPT. Genotypes LITTH-778, LITTH-784, LITTH786, LITTH-788, and LITTH-790 of NST fruits had crude fat of $0.32,0.30,0.27,0.29$, and $0.28 \mathrm{~g} / 100 \mathrm{~g}$, respectively, which were less than the crude fat of NPT fruits. Similarly genotype of NST showed less fiber contents than NPT (Table 1). Variations in crude fat and crude fiber contents among the genotypes of NPT and NST were found significant $(p \leq 0.05)$. Similarly, the total carbohydrates were also high in NPT fruits having no seeds. It might be due to the accumulation of more starch and its subsequent conversion to sugar that is one of the most striking differences between the NPT and NST as observed in present studies. High amount of total carbohydrate was observed in LITTH-778 (1.33 g/100 g) from NST and LITTH-788 $(3.93 \mathrm{~g} / 100 \mathrm{~g})$ from NPT.

For the proper growth and maintenance of human body, proteins play key role and, along with lipids and carbohydrates, act as energy source. They also control the vital body function such as nutrients transport, enzymatic activity, and other biological compounds across the cell membrane [29]. The crude fruits proteins of NST genotypes of LITTH-778, LITTH-784, LITTH-786, LITTH-788, and LITTH-790 were $2.65,1.72,3.75,2.77$, and $1.69 \mathrm{~g} / 100 \mathrm{~g}$ which were lower than crude protein of NPT fruits (Table 2). The variations of crude protein in NPT and NST fruits were found to be significantly 


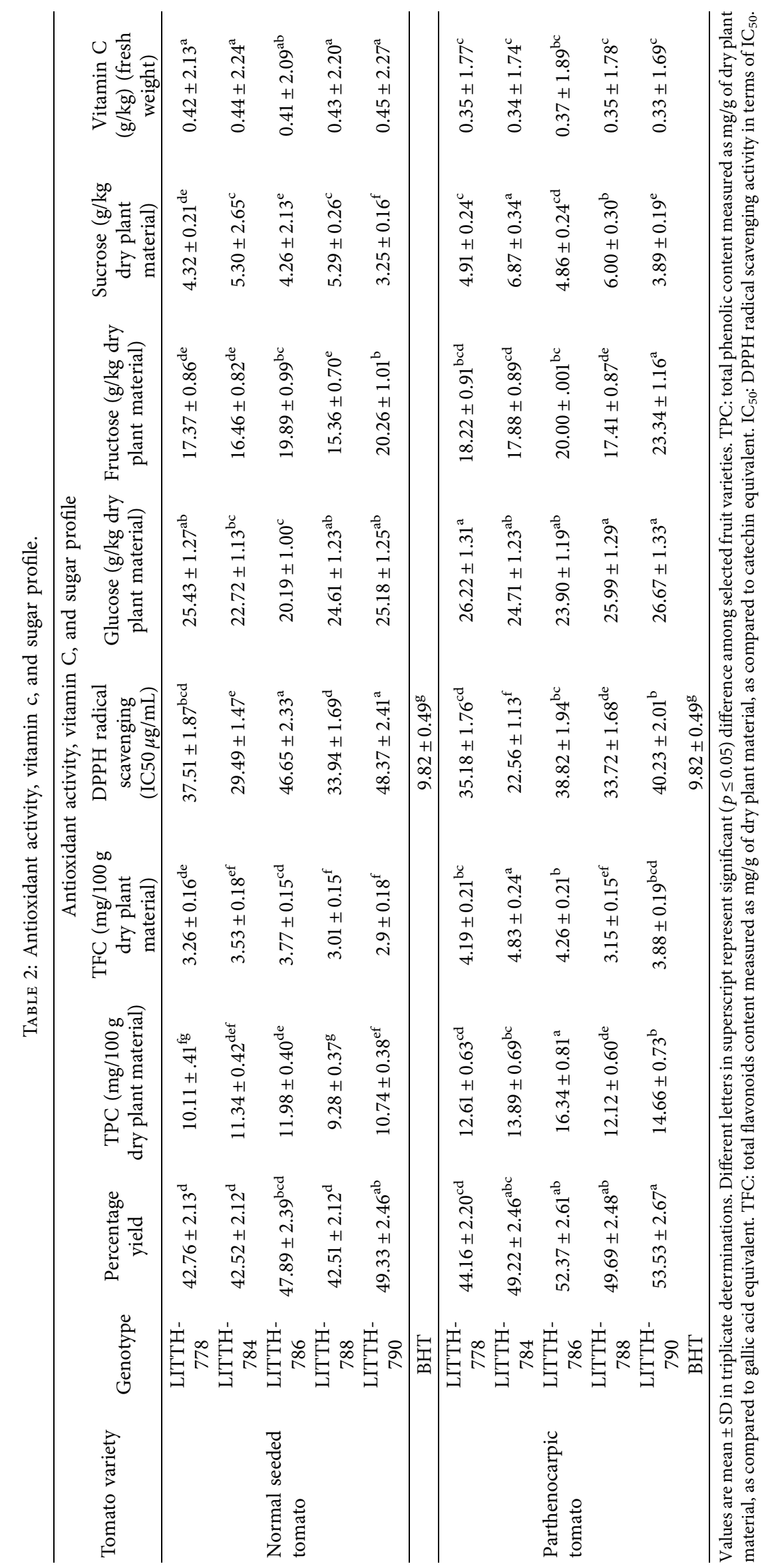


different $(p \leq 0.05)$. Our findings regarding fruits proximate composition of NPT and NST genotypes were comparable with earlier findings in different tomato varieties as studied by different researches [28-30].

3.3. Extract Yields. The percent yields of $\mathrm{MeOH}$ extracts of NST and NPT fruits are presented in Table 2, which ranged in $42.51-49.33 \mathrm{~g} / 100 \mathrm{~g}$ of dry fruits (W/W) and $44.16-53.53 \mathrm{~g} / 100 \mathrm{~g}$ of dry fruits (W/W), respectively. Difference in the percent yields of $\mathrm{MeOH}$ extract might be due to variation in different extractable compounds. Previously reported data revealed that polar solvents are used for the extraction polyphenols because of their polarity and compatibility [31].

3.4. TPC, TFC, and Antioxidant Activity of the Extracts. Total phenolic contents (TPC) of NST and NPT fruit extracts were measured and reported as gallic acid equivalent (Table 2). Total phenolic contents of NST and NPT fruit extracts were in the range of $9.28-11.98$ and $12.12-14.66 \mathrm{mg} / 100 \mathrm{~g}$ dry matter, respectively. The highest TPC was observed in the extract of LITTH-786 from NST and LITTH-786 from NPT whereas the lowest was for LITTH-788 from NST and LITTH-788 from NPT. Generally the significantly $(p \leq 0.05)$ higher TPC was found in NPT as compared to NST. TFC of the NST and NPT fruit extracts tomatoes were measured in terms of catechin equivalent (Table 2). TFC of NST fruit extracts were less than NPT with the range of 2.9-3.77 and $3.15-4.83 \mathrm{mg} / 100 \mathrm{~g}$ dry material, respectively. Some reports available in literature confirmed the high TPC and TFC in various genotypes of tomatoes and our results are comparable with those reports [28-30].

Free radical scavenging activity, as measured in the DPPH radial scavenging assay, increased with an increase of extract concentrations and extract concentrations providing $50 \%$ scavenging $\left(\mathrm{IC}_{50}\right)$ are shown in Table 2 . NPT and NST fruits extract exhibited significantly different radical scavenging activity. NPT fruit extracts showed better DPPH radical scavenging activity with the IC50 values of $22.56-40.23 \mu \mathrm{g} / \mathrm{mL}$, whereas NST fruit extract showed lesser activity with the IC50 values of $29.49-48.37 \mu \mathrm{g} / \mathrm{mL}$. The significant differences $(p \leq 0.05)$ in DPPH radical scavenging of different tomato genotypes were observed and data showed parthenocarpy has improved the DPPH radical scavenging activity that could be attributed to their better TPC and TFC.

3.5. Vitamin Cand Sugar Contents. Vitamin C concentration in NST and NPT fruits extract is shown in Table 2. Genotypes of NST showed high vitamin C concentration (0.41-0.45 g/ $\mathrm{kg}$ ) followed by NPT fruits with concentration of $0.33-0.37 \mathrm{~g} / \mathrm{kg}$. Results are comparable with the findings of Abdullah et al., who reported the presence of vitamin $\mathrm{c}$ and mineral in the fresh tomatoes [28].
The sugar contents found in the NPT and NPT fruit extracts in the present study are shown in Table 2. Sugar contents of NPT fruits had higher levels of glucose $(24.71-26.67 \mathrm{~g} / \mathrm{kg} \mathrm{fw})$, fructose $(17.41-23.34 \mathrm{~g} / \mathrm{kg} \mathrm{fw})$, and sucrose $(3.89-6.87 \mathrm{~g} / \mathrm{kg} \mathrm{fw})$ than NST fruits having glucose (20.19-25.43 g/kg fw), fructose (15.36-20.26 g/kg fw), and sucrose $(0.41-0.45 \mathrm{~g} / \mathrm{kg} \mathrm{fw})$. These sugars are the major source of energy for metabolism in living organism [29]. Parthenocarpic tomatoes had better nutritional values in terms of carbohydrate/sugar than normal seeded tomato fruits. The present results were comparable to previously reported data on tomato puree [30].

3.6. HPLC Estimation of Phenolics and Flavonoids. The amounts $(\mathrm{mg} / 100 \mathrm{~g}$ of dry material) of eight detectable phenolic acids in the $\mathrm{MeOH}$ extracts are reported in Table 3. Gallic acid (1), chlorogenic acid (2), p-hydroxy benzoic acid (3), caffeic acids (4), vanillic acid (5), p-coumaric acid (6), sinapic acid (7), and the ferulic acid (8) were the major phenolic acids detected (Figure 3). Catechin (9), quercetin (10), and kaempferol (11) were the major flavonoids detected in NST and NPT fruit extracts (Figure 2). Overall chlorogenic acid was found to be the major phenolic acid in the $\mathrm{MeOH}$ extract of NST genotypes ranging between 1116.67 and $1163.1 \mathrm{mg} / 100 \mathrm{~g}$ of dry plant material followed by gallic acid (603.9-677.7 mg/100 g of dry plant material), $p$-coumaric acid (50.06-56.5 mg/100 g of dry plant material), $p$ hydroxy benzoic acid $(15.5-21.2 \mathrm{mg} / 100 \mathrm{~g}$ of dry plant material), ferulic acid $(6.09-9.9 \mathrm{mg} / 100 \mathrm{~g}$ of dry plant material), caffeic acid (2.4-3.2 mg/100 g of dry plant material), and vanillic acid (1.1-1.7 mg/100 g of dry plant material), whereas quercetin was separated as the major flavonoid with the concentration range of $122.01-149.5 \mathrm{mg} / 100 \mathrm{~g}$ of dry plant material followed by catechin $(54.55-84.3 \mathrm{mg} / 100 \mathrm{~g}$ of dry plant material) and kaempferol $(13.3-19.7 \mathrm{mg} / 100 \mathrm{~g}$ of dry plant material) (Figure 3).

Similarly caffeic acid was found to be major phenolic acid in methanolic extract of NPT genotypes (1999.2-2200.6 mg/100 g of dry plant material) followed by p-coumaric acid (1795.2-1971.6 mg/100 g of dry plant material), gallic acid $(240.2-272.3 \mathrm{mg} / 100 \mathrm{~g}$ of dry plant material), sinapic acid $(226.8-254.5 \mathrm{mg} / 100 \mathrm{~g}$ of dry plant material), ferulic acid $(151.5167 .4 \mathrm{mg} / 100 \mathrm{~g}$ of dry plant material), $p$-hydroxy benzoic acid (109.9-117.4 mg/100 $\mathrm{g}$ of dry plant material), vanillic acid (101.3-113.2 mg/100 g of dry plant material), and chlorogenic acid $(69.9-81.1 \mathrm{mg} /$ $100 \mathrm{~g}$ of dry plant material) (Figure 2). The highest amount of flavonoid was kaempferol (311.1-320.4 mg/100 g of dry plant material) followed by catechin $(266.3-297.7 \mathrm{mg} / 100 \mathrm{~g}$ of dry plant material) and quercetin $(264.7-305.8 \mathrm{mg} / 100 \mathrm{~g}$ of dry plant material) (Figure 2). All individual phenolic acids identified were at the higher level in NPT fruit extracts than NST fruit extracts. Significant $(p \leq 0.05)$ variations were observed in the contents of phenolic acids and flavonoids among different genotypes of the fruits. Our findings regarding phenolic profile and flavonoids are in agreement 


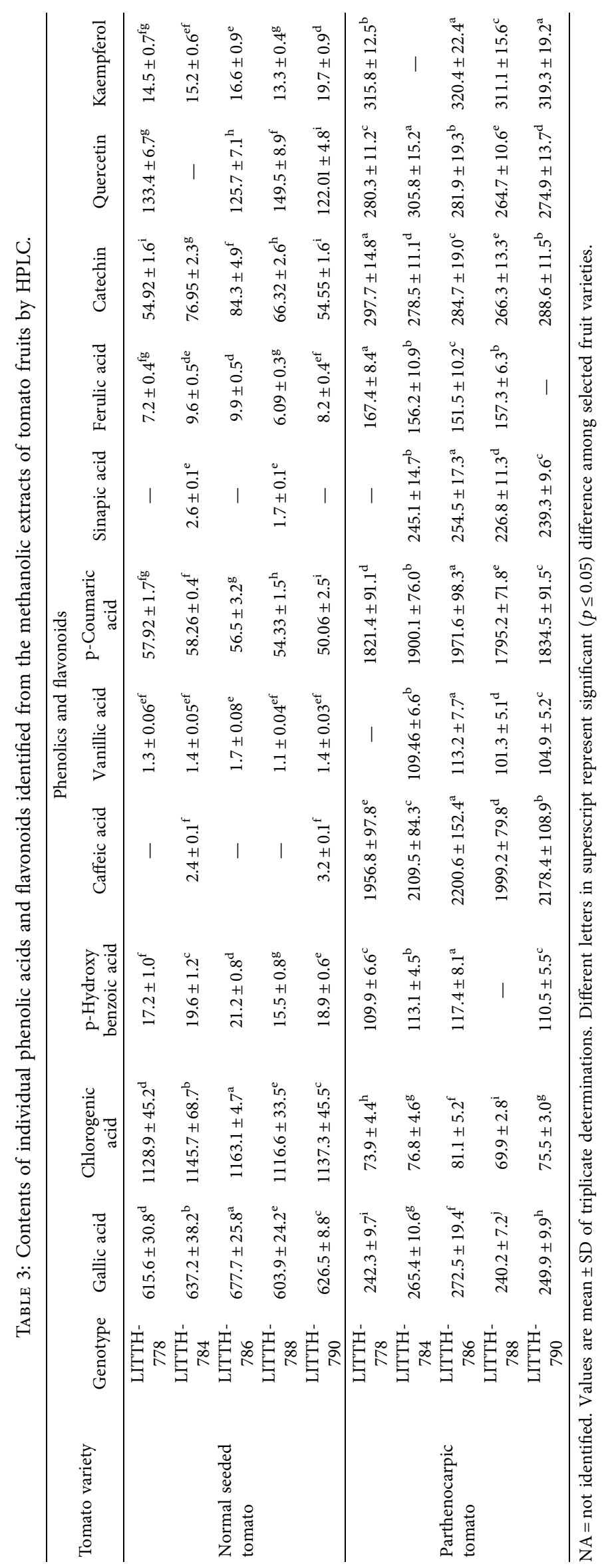




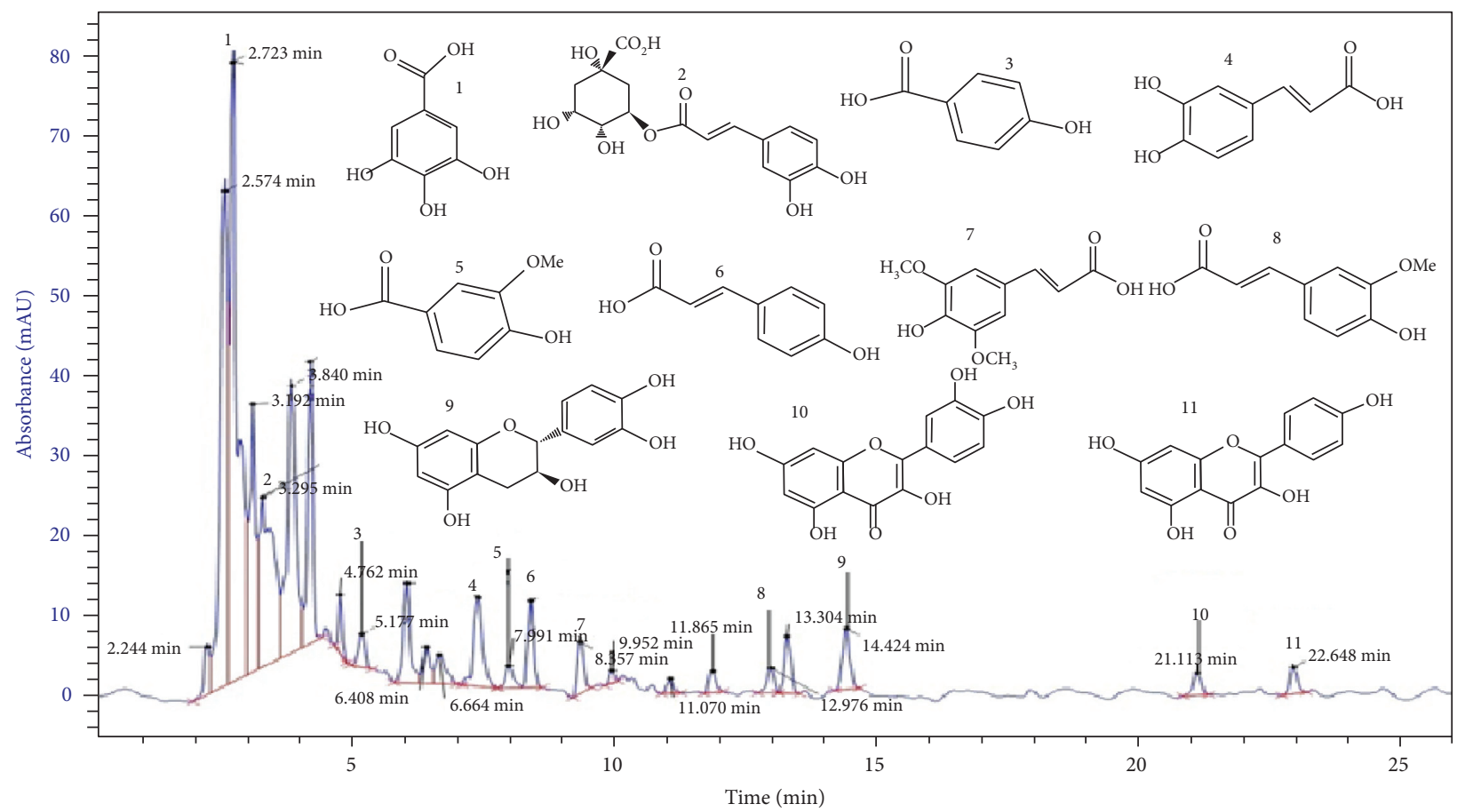

Figure 2: Typical chromatogram of phenolic acid and flavonoids of parthenocarpic tomatoes. (1) Gallic acid, (2) chlorogenic acid, (3) $p$ hydroxy benzoic acid, (4) caffeic acid, (5) vanillic acid, (6) p-coumaric acid, (7) sinapic acid, (8) ferulic acid, (9) catechin, (10) quercetin, and (11) kaempferol.

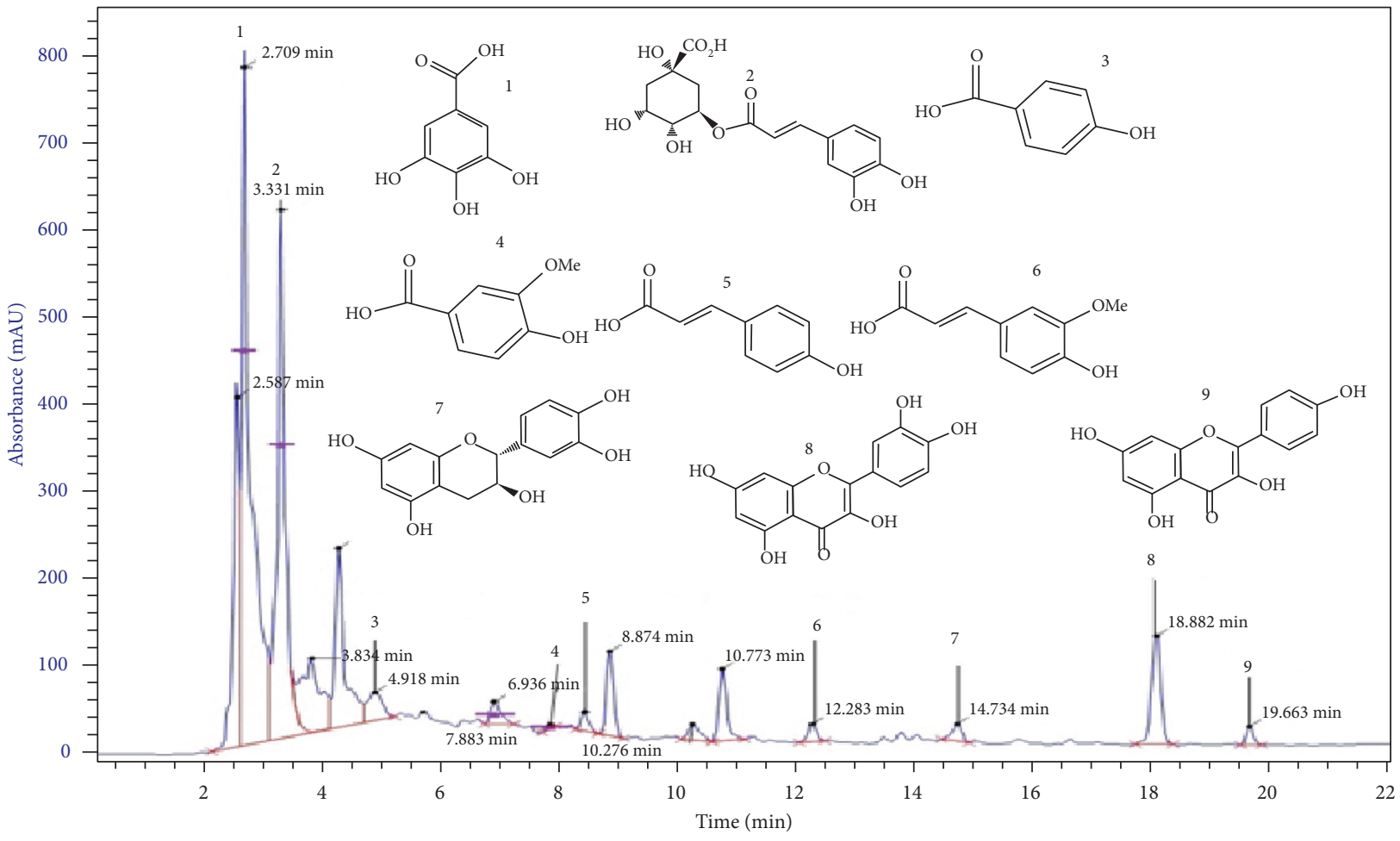

FIGURE 3: Typical chromatogram of phenolic acid and flavonoids of normal seeded tomatoes. (1) Gallic acid, (2) chlorogenic acid, (3) phydroxy benzoic acid, (4) vanillic acid, (5) p-coumaric acid, (6) ferulic acid, (7) catechin, (8) quercetin, and (9) kaempferol. 
with the findings of Silva-Beltrán et al. [32] who reported the presence of gallic acid, chlorogenic acid, caffeic acid, ferulic acid, rutin, and quercetin in tomatoes extracts.

\section{Conclusions}

This is the first study revealing the comparison of physical parameters, nutritional composition, antioxidant activity, vitamin C, sugar contents, phenolics, and flavonoids profiles of NPT and NST genotype of tomatoes. Parthenocarpy appears to be an important trait for improving the yield, quality, and processing traits of vegetable crops. Parthenocarpy could not only increase the production and nutritional quality of tomato fruits but also increase the sugar contents and decrease vitamin $\mathrm{C}$, which increased the shelflife of fruits. Parthenocarpic tomato also showed high antioxidant activity due to the presence of high amounts of phenolics and flavonoids contents. The current findings could potentially assist the food technologists and nutritional professionals in recommending the use of parthenocarpic tomato fruits in human diets directly or as additives in food products due to their high sugar content, phenolics, and flavonoids.

\section{Data Availability}

The supporting data for findings of the present study are included in the article.

\section{Conflicts of Interest}

The authors declare no conflicts of interest.

\section{Acknowledgments}

Facilities provided by Central Hi Tech Lab, Government College University, Faisalabad, for HPLC analysis are highly acknowledged. The authors would like to extend their sincere appreciation to the Researchers Supporting Project no. RSP-2021/182, King Saud University, Riyadh, Saudi Arabia.

\section{References}

[1] P. P. V. Grimault and J. Sehmit, "Resistanee to baeterial wilt (Pseudomonas solanaeearum) in tomato: present status and prospeets," in Bacterial Wilt: The Disease And Its Causative Agent, Pseudomonas solanaeearum, A. C. Hayward and G. L. Hartman, Eds., Vol. 209, CAB International, Wallingford, UK, 1994.

[2] G. Giovanelli and A. Paradiso, "Stability of dried and intermediate moisture tomato pulp during storage," Journal of Agricultural and Food Chemistry, vol. 50, pp. 7277-7281, 2002.

[3] G. Tamasi, A. Pardini, C. Bonechi et al., "Characterization of nutraceutical components in tomato pulp, skin and locular gel," European Food Research and Technology, vol. 245, no. 4, pp. 907-918, 2019.

[4] S. Agarwal and A. V. Rao, "Tomato lycopene and its role in human health and chronic diseases," Canadian Medical Association Journal: Canadian Medical Association Journal, vol. 163, pp. 739-744, 2000.
[5] C. Pinto, B. Rodriguez-Galdon, J. J. Cestero, and P. Macias, "Processed tomatoes improves the antioxidant status of carbon tetrachloride-intoxicated rat tissues," European Food Research and Technology, vol. 244, no. 10, pp. 1843-1852, 2018.

[6] A. R. Zangerl, M. R. Berenbaum, and J. K. Nitao, "Parthenocarpic fruits in wild parsnip: decoy defence against a specialist herbivore," Evolutionary Ecology, vol. 5, no. 2, pp. 136-145, 1991.

[7] M. E. Picarella and A. Mazzucato, "The occurrence of seedlessness in higher plants; insights on roles and mechanisms of parthenocarpy," Frontiers of Plant Science, vol. 9, p. 1997, 2019.

[8] F. Varoquaux, R. Blanvillain, M. Delseny, and P. Gallois, "Less is better: new approaches for seedless fruit production," Trends in Biotechnology, vol. 18, no. 6, pp. 233-242, 2000.

[9] F. Martinelli, S. L. Uratsu, R. L. Reagan et al., "Gene regulation in parthenocarpic tomato fruit," Journal of Experimental Botany, vol. 60, no. 13, pp. 3873-3890, 2009.

[10] G. L. Rotino, E. Perri, M. Zottini, H. Sommer, and A. Spena, "Genetic engineering of parthenocarpic plants," Nature Biotechnology, vol. 15, no. 13, pp. 1398-1401, 1997.

[11] S. Maqsood, O. Adiamo, M. Ahmad, and P. Mudgil, "Bioactive compounds from date fruit and seed as potential nutraceutical and functional food ingredients," Food Chemistry, vol. 308, Article ID 125522, 2020.

[12] T. Pandolfini, "Seedless fruit production by hormonal regulation of fruit set," Nutrients, vol. 1, no. 2, pp. 168-177, 2009.

[13] W. A. H. Champa, M. I. S. Gill, B. V. C. Mahajan, and N. K. Arora, "Postharvest treatment of polyamines maintains quality and extends shelf-life of table grapes (Vitis vinifera L.) cv. Flame Seedless," Postharvest Biology and Technology, vol. 91, pp. 57-63, 2014.

[14] G. P. Soressi and F. A. Salamini, "Monomendelian gene inducing parthenocarpic fruits," Report of the Tomato Genetics Cooperative, vol. 25, no. 22, 1975.

[15] M. Fos, K. Proaño, F. Nuez, and J. L. García-Martínez, "Role of gibberellins in parthenocarpic fruit development induced by the genetic systempat-3/pat-4 in tomato," Physiologia Plantarum, vol. 111, no. 4, pp. 545-550, 2001.

[16] Z. Hu, S. Lan, N. Zhao et al., "Soft-X-irradiated pollens induce parthenocarpy in watermelon via rapid changes of hormonesignalings and hormonal regulation," Scientia Horticulturae, vol. 250, pp. 317-328, 2019.

[17] C. Clepet, R. S. Devani, R. Boumlik et al., "The miR166SIHB15A regulatory module controls ovule development and parthenocarpic fruit set under adverse temperatures in tomato," Molecular Plant, vol. 14, 2021.

[18] J. R. Baggett and W. A. Frazier, "Oregon T5-4 parthenocarpic tomato line,” HortScience, vol. 13, no. 5, p. 599, 1978.

[19] J. Casals, L. Pascual, J. Cañizares, J. Cebolla-Cornejo, F. Casañas, and F. Nuez, "Genetic basis of long shelf life and variability into Penjar tomato," Genetic Resources and Crop Evolution, vol. 59, no. 2, pp. 219-229, 2012.

[20] D. R. Osborne and P. Voogt, "Calculation of calorific value," The analysis of Nutrients in Foods, pp. 239-240, 1978.

[21] AOAC, Official Methods of Analysis, Sidney Willians, Washington, D. C., USA, 1980.

[22] K. K. Eyeson and E. K. Ankrah, Composition of Foods Commonly Used in Ghana, Council for Scientific and Industrial Research (CSIR), Food Research Institute, Accra, Ghana, 1975.

[23] B. Sultana, F. Anwar, and M. Ashraf, "Effect of extraction solvent/technique on the antioxidant activity of selected 
medicinal plant extracts," Molecules, vol. 14, no. 6, pp. 2167-2180, 2009.

[24] A. I. Hussain, H. A. Rathore, M. Z. A. Sattar et al., "Phenolic profile and antioxidant activity of various extracts from Citrullus colocynthis (L.) from the Pakistani flora," Industrial Crops and Products, vol. 45, pp. 416-422, 2013.

[25] L. Barros, A. M. Carvalho, and I. C. F. R. Ferreira, "Leaves, flowers, immature fruits and leafy flowered stems of Malva sylvestris: a comparative study of the nutraceutical potential and composition," Food and Chemical Toxicology, vol. 48, no. 6, pp. 1466-1472, 2010.

[26] C. Alasalvar, J. M. Grigor, D. Zhang, P. C. Quantick, and F. Shahidi, "Comparison of volatiles, phenolics, sugars, antioxidant vitamins, and sensory quality of different colored carrot varieties," Journal of Agricultural and Food Chemistry, vol. 49, no. 3, pp. 1410-1416, 2001.

[27] A. P. Sobolev, A. Neelam, T. Fatima, V. Shukla, A. K. Handa, and A. K. Mattoo, "Genetic introgression of ethylene-suppressed transgenic tomatoes with higher-polyamines trait overcomes many unintended effects due to reduced ethylene on the primary metabolome," Frontiers of Plant Science, vol. 5, p. 632, 2014.

[28] I. I. Abdullahi, N. Abdullahi, A. Muhammad Abdu, and A. S. Ibrahim, "Proximate, mineral and vitamin Analysis of fresh and canned tomato," Biosciences, Biotechnology Research Asia, vol. 13, no. 2, pp. 1163-1169, 2016.

[29] A. Gupta, A. Kawatra, and S. Sehgal, "Physical-chemical properties and nutritional evaluation of newly developed tomato genotypes," African Journal of Food Science and Technology, vol. 2, pp. 167-172, 2011.

[30] J. Pinela, L. Barros, A. M. Carvalho, and I. C. Ferreira, "Nutritional composition and antioxidant activity of four tomato (Lycopersicon esculentum L.) farmer' varieties in Northeastern Portugal homegardens," Food and Chemical Toxicology: An International Journal Published for the British Industrial Biological Research Association, vol. 50, no. 3-4, pp. 829-834, 2012.

[31] H. Mabrouki, C. M. M. Duarte, and D. E. Akretche, "Estimation of total phenolic contents and in vitro antioxidant and antimicrobial activities of various solvent extracts of Melissa officinalis L," Arabian Journal for Science and Engineering, vol. 43, no. 7, pp. 3349-3357, 2018.

[32] N. P. Silva-Beltrán, S. Ruiz-Cruz, C. Chaidez et al., "Chemical constitution and effect of extracts of tomato plants byproducts on the enteric viral surrogates," International Journal of Environmental Health Research, vol. 25, no. 3, pp. 299-311, 2015. 